M.J. Girotti MD FRCSC, K. Hong BSC M SC, W.C. Demajo MD FRCPC, T.R.J. Todd MD FRCSC

\section{Comparison of regional pulmonary perfusion in lobar pneumonia during high frequency and conventional mechanical ventilation in sheep}

High frequency ventilation has been shown to produce equivalent arterial oxygenation and alveolar ventilation in normal and diseased pulmonary parenchyma when compared to conventional mechanical ventilation.' Clinical and basic research has attempted to define the physiological mechanisms of gas exchange, the potential for reduced lung injury, the cffects on hacmodynamic function, and the mechanical properties of this new ventilatory technique. ${ }^{1-5}$

In the clinical setting of the adult respiratory distress syndrome, pneumonitis or other conditions which result in ventilation/perfusion inhomogeneity, improved oxygenation may be the result of altered regional pulmonary perfusion as much as enhanced ventilation. ${ }^{2.6}$ In contrast to clinical events such as pulnonary embolism or tobar atelectasis, pneumonic infiltration of the lung has been demonstrated to partially impair expected hypoxaemic vasoconstriction of the involved lung units during conventional mechanical ventilation. ${ }^{7}$ Local release of inflammatory substances which are known vasodilators may mediate this response.

Various products of the arachadonic acid pathway have been suggested as mediators of the normal hypoxic pulmonary vasoconstrictive response which attempts to reduce the observed ventilation/perfusion inhomogeneity. ${ }^{8,9}$ Pulmonary blood flow may be modified by active secretion of these vasoactive substances in response to various pathophysiological and mechanical stimuli. ${ }^{10-12}$ Mechanical ventilation itself may contribute to a redistribution of pulmonary blood flow due to changes in arachadonic acid metabolism. As a result, different modes of ventilation may have distinctly different effects on pulmonary blood flow.

The purpose of this experiment was to compare the effect of high frequency jet ventilation (HFV), conventional mechanical ventilation (CMV), and spontaneous 
breathing (SB) on regional pulmonary blood flows, standard cardiopulmonary variables and plasma levels of prostacyclin and thromboxane $A_{2}$ in cstablished lobar gram negative pneumonitis in sheep. Ventilator settings for both HFV and CMV closely resembled those which are used for acute adult respiratory failure.

\section{Methods}

Adult Suffolk-Dorset sheep weighing between $30-40 \mathrm{~kg}$ were sedated intramuscularly with ketamine $\left(30 \mathrm{mg} \cdot \mathrm{kg}^{-1}\right)$. Through a cervical incision, polyethylene catheters were introduced into the common carotid artery and the internal jugular vein. A pulmonary artery catheter (Edwards, model 93-1317) was floated into a pulmonary artery under pressure control. All pressures were measured using Statham ID-PD 33 transducers connected to a multichannel physiograph (Hewlett-Packard, model \#7780). The right shoulder was used as a constant reference point. Cardiac outputs were determined in triplicate by the thermodilution technique on a standard cardiac output calculator (Edwards cardiac, model \#9510). Blood gas determinations were carried out on a Corning Blood Gas analyzer (model \#168).

Lobar pseudomonas pneumonia in sheep has been previously reported by our laboratory. ${ }^{13}$ Under ketamine anaesthesia, with the sheep in a prone position, the animals underwent flexible bronchoscopy through an endotracheal tube. A total of $2.5 \mathrm{ml}$ of brain heart broth containing $10^{8}-10^{10}$ live pscudomonas acroginosa (Fischer Type IV) organisms were directly instilled into the left lower lobe (LLL) bronchus. This results in a reproducible gravity dependent left lower lobe pneumonia which varies slightly in size. ${ }^{13}$

Regional pulmonary blood flows (PBF) were measured using radioactive microspheres $\left({ }^{153} \mathrm{Gd},{ }^{113} \mathrm{Sn},{ }^{46} \mathrm{Se}\right)$ in jected into the internal jugular venous catheter. Each selected microsphere has a distinct gamma energy emission that is easily recognized in a multichannel gamma counter. The microspheres $\left(2 \times 10^{6}\right)$ were suspended in five per cent dextrose/water and injected by pressurized flow during mechanical agitation in a specially designed microsphere agitation chamber over a 90 -second period of time. Separate microsphere injections were performed in order to evaluate total and regional PBF during each ventilatory mode.

Plasma levels of 6-keto prostaglandin $F_{1}$ (6-keto-PGF 1 ) and thromboxane $\mathrm{B}_{2}\left(\mathrm{TKB}_{2}\right)$, the stable hydrolysis products of prostacyclin $\left(\mathrm{PGI}_{2}\right)$ and thromboxane $\mathrm{A}_{2}$ (TxA $\mathrm{A}_{2}$ ), were measured by a radioimmunoassay described previously. $^{14}$

CMV was carried out by a Medi-Shields volume cycled ventilator (model \#10). Standard CMV settings were respiratory rate (RR) $24 \cdot \mathrm{min}^{-1}$, tidal volume (TV) 15 $\mathrm{ml} \cdot \mathrm{kg}^{-1}$, positive end expiratory pressure (PEEP) 0 , and fractional inspired oxygen concentration $\left(\mathrm{FtO}_{2}\right) 0.3$.

HFV was produced using a microprocessor-based tither which drives a solenoid valve. This high frequency ventilator allows independent adjustment of RR, inspiratory: expiratory ratio (I:E), driving pressure (DP), PEEP, and $\mathrm{FIO}_{2}$. The inspired gases are delivered through noncompliant Teflon tubing to an injector cannula (inner diameter $3 \mathrm{~mm}$ ) placed through a swivel connector in the endotracheal tube. This ventilator was set at: RR $120 \cdot \mathrm{min}^{-1}$, DP 6 psi, I:E 0.35, PEEP 0, and $\mathrm{FIO}_{2} 0.3$

\section{Experimental protocol}

This protocol was approved by the Animal Ethics Committee of the University of Toronto, Toronto, Canada.

Each individual experiment covered a 52-hour period. On day one, all animals underwent carotid and pulmonary arterial cannulation. Three independent study periods were defined thereafter:

- SB: 4 hrs post-cannulation; baseline measurements of blood pressure (BP), pulmonary artery pressure (PAP), cardiac output (CO), arterial and yenous blood gases, PBF, and blood samples for prostaglandin analysis; bronchoscopic introduction of pseudomonas bacteria into LLL.

- SB + PN: 48 hrs after induction of pneumonia; repeat all baseline measurements.

- VENT + PN: immediately following the SB + PN measurement, all animals were anaesthetized (pentobarbitone $30 \mathrm{mg} \mathrm{kg}^{-1}$ ), intubatcd, and paralyzed (pancuronium $0.1 \mathrm{mg} \cdot \mathrm{kg}^{-\mathrm{l}}$ ); sedation was maintained by fentanyl in $25 \mu \mathrm{g}$ aliquots intravenously; ventilation sandomly proceeded with ejther $\operatorname{CMV}(n=6)$ or HFV $(n=5)$ until the desired arterial blood gases were recorded for a minimum of a 20-minute stable period; all measurements were repeated; animals were then sacrificed by barbicurate overdose.

Minor adjustments in ventilator settings were made during VENT + PN (TV or DP for $\mathrm{PaCO}_{2}$ and $\mathrm{FIO}_{2}$ for $\mathrm{PaO}_{2}$ ) in such a way as to produce arterial blood gases similar to measured values during the $\mathrm{SB}+\mathrm{PN}$ period $\left(\mathrm{PaO}_{2} \pm 10 \mathrm{mmHg}, \mathrm{PaCO}_{2} \pm 5 \mathrm{mmHg}\right.$ ).

Post-sacrifice, the lungs were harvested and allowed to passively drain free of blood for one hour and then air dried via constant air flow at $30 \mathrm{~cm} \mathrm{H}_{2} \mathrm{O}$ of distending pressure through the intubated trachea. The LLL of the excised lungs was weighed and homogenized in a Waring blender with water. Samples were withdrawn for gamma counting. The remaining whole lungs were similarly treated.

All measurements during SB and SB + PN were made with the animals awake standing in their cages. All measurements during VENT + PN were made with the 
TABLE I Comparisons of measured cardiopulmonary variables during various ventilatory modes (SB, SMV, HFV) with and without pncumonia (SB, SB + PN, VENT + PN)

\begin{tabular}{|c|c|c|c|c|}
\hline & $\begin{array}{l}\text { Mean } \\
P A \\
\left(m m H_{g}\right)\end{array}$ & $\begin{array}{l}\text { Cardiac } \\
\text { outpu } \\
\left(L \cdot \min ^{-1}\right)\end{array}$ & $\begin{array}{l}\mathrm{PaO}_{2} \\
\left(m m H_{g}\right)\end{array}$ & $\begin{array}{l}\text { Meat blood } \\
\text { pressure } \\
\text { (ntm } H_{g} \text { ) }\end{array}$ \\
\hline $\begin{array}{l}5 \mathrm{~B}: \\
(\mathrm{N}=11)\end{array}$ & $18 \pm 4^{*}$ & $5.3 \pm 0.3^{*}$ & $99 \pm 5^{*}$ & $94 \pm 10^{*}$ \\
\hline $\begin{array}{l}\mathrm{SB}+\mathrm{PN}: \\
(\pi=11)\end{array}$ & $23 \pm 6^{*}$ & $5.0 \pm 1.2^{*}$ & $79 \pm 8 \dagger$ & $95 \pm 16^{*}$ \\
\hline $\begin{array}{l}\text { VENT + PN: } \\
\text { CYV }(n=6) \\
\text { HFV }(n=5)\end{array}$ & $\begin{array}{l}27 \pm 7^{*} \\
19 \pm 10^{*}\end{array}$ & $\begin{array}{l}4.1 \pm 0.7^{*} \\
5.3 \pm 1.2^{*}\end{array}$ & $\begin{array}{l}88 \pm 12^{*} \\
87 \pm 6^{*}\end{array}$ & $\begin{array}{l}116 \pm 7 \dagger \\
107 \pm 10 \dagger\end{array}$ \\
\hline
\end{tabular}

*, + Indicate statistically different group means by Kruskal-Wallis modification of ANOVA $(\mathrm{H}<0.05$ ).

animals in the prone position. The order, the method of ventilation and identity of the microspheres wcrc randomly assigned. During VENT + PN, the animals received normal saline intravenously.

\section{Data analysis}

Standard formulae were used to calculate the shunt fraction (Qs/Qt), and the alveolar-arterial oxygen gradient [(A-a) $\mathrm{DO}_{2}$ ]. Regional left lower lobe perfusion $\left(\mathrm{Q}_{\mathrm{LLL}}\right)$ was calculated as a percentage of cardiac output:

$\mathrm{Q}_{\mathrm{LLL}}=\frac{\mathrm{C}_{\mathrm{LLL}}}{\mathrm{C}_{\mathrm{TOT}}} \times \mathrm{CO} \times 100 \%$

where $C_{L L L}$ and $C_{T O T}$ are the radioactive counts in the LLL and the total lung respectively $\left(\mathrm{C}_{\mathrm{LLL}}=\right.$ weight $_{\mathrm{LLL}} \mathrm{gms}$ $x$ counts $/ g m_{\text {LLL }}$ ).

All data are reported as the mean \pm standard deviation. Statistical comparisons of group means of study parameters were done using the Kruskal-Wallis modification of the analysis of variance. ${ }^{15}$ Statistical significance was achieved at $\mathrm{H}<0.05$. Correlation analyses of $Q_{L L L}$ and the $P I_{2}$ and thromboxane $A_{2}$ serum levels were done using the Spearman coefficient. ${ }^{16}$

\section{Results}

Eleven animals successfully completed the experimental protocol. At $\mathrm{SB}+\mathrm{PN}$, all sheep were observed to be anorexic, tachypnoeic, febrile and have productive coughs. At autopsy, all animals had a significant LLL consolidative process following a dependent distribution and grossly showing minor variations in size. During VENT + PN, no significant changes in ventilator settings for $\mathrm{CMV}$ or HFV between different animals were made. The mean $\mathrm{FiO}_{2}$ during CMV or HFV ventilation was 0.28 with a range of $0.24-0.44$. The TV was increased to a maximum of $18 \mathrm{ml} \cdot \mathrm{kg}^{-1}$. The DP was incrcased to a maximum of $8 \mathrm{psi}$. Intravenous saline requirements during VENT + PN never exceeded $500 \mathrm{ml}$.

At time SB + PN, all animals were significantly hypoxaemic (Table I). Other measured arterial blood gas variables $\left(\mathrm{pH}, \mathrm{PaCO}_{2}\right)$ did not change significantly. Mean PAP increased but did not reach statistical significance. Ventilation with HFV and CMV resulted in significant increases in mean BP only. Table II records the changes observed in (A-a)DO $\mathrm{D}_{2}$ and Qs/Qt. Pneumonia resulted in a significant increase in both the $\mathrm{Qs} / \mathrm{Q}$ t and the $(\mathrm{A}-\mathrm{a}) \mathrm{DO}_{2}$ compared to SB. Ventilation with either HFV or CMV caused a further significant rise in $(A-a) D_{2}$ compared to the SB + PN and SB periods, but were no different from one another. Qs/Qt during VENT + PN did not significantly change from the SB + PN period for either mode of ventilation.

QLLL over the experiment is displayed in Figure 1. $Q_{L L L}$ significantly decreased at SB + PN when compared to SB. Ventilation with either CMV or HFV caused no significant differences in $Q_{L L L}$ when compared to each other or to the $\mathrm{SB}$ or $\mathrm{SB}+\mathrm{PN}$ periods. Although not statistically different, opposite directional changes in QLLL were noted during CMV and HFV ventilation periods.

The serum levels of 6-keto $\mathrm{PGF}_{1} \alpha$ and $\mathrm{TxB}_{2}$ at the study periods are shown in Figure 2. Large standard deviations in these assays were recorded. Statistical significance of group means by ANOVA was observed for the 6-keto-PGF $\alpha$ serum level when HFV was compared to CMV only. Otherwise all other comparisons of 6-keto$P G F_{1} \alpha$ and $T \times B_{2}$ levels were not significantly different at any study period.

Significant correlations between $\mathrm{Q}_{\mathrm{LLL}}$ and either the 6-keto-PGF ${ }_{1} \alpha$ or the $\mathrm{TxB}_{2}$ serum measurements during

TABLE Il Comparisons of calculated haemodynamic variables during various ventilatory modes (SB,CMV, HFV) with and without pneumonia (SB, SB + PN, VENT + PN)

\begin{tabular}{lll}
\hline & $\begin{array}{l}(A-a) D O_{2} \\
(\mathrm{mmHg})\end{array}$ & $\begin{array}{l}Q s / Q I \\
(\%)\end{array}$ \\
\hline $\begin{array}{l}\mathrm{SB}: \\
(\mathrm{n}=11)\end{array}$ & $15 \pm 3^{*}$ & $9.0 \pm 3.4^{*}$ \\
$\mathrm{SB}+\mathrm{PN}:$ & \\
$(\mathrm{n}=11)$ & $34 \pm 5.5 \dagger$ & $18.0 \pm 6.7 \dagger$ \\
$\begin{array}{l}\text { VENT + PN: } \\
\text { CMV (n=6) }\end{array}$ & $90 \pm 14 \ddagger$ \\
HFV (n=5) & $70 \pm 21 \ddagger$ & $23.0 \pm 6.2 \dagger$ \\
\hline
\end{tabular}

$*, t, \neq$ Indicate statistically different group means by kruskal-Wallis modification of ANOVA $(\mathrm{H}<0.05)$ 


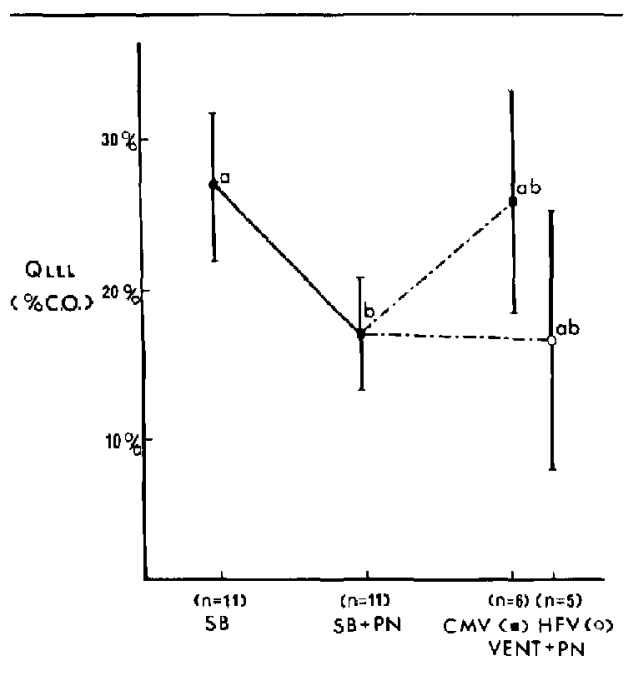

FIGURE 1 Regional pulmonary blood (QLL) to pncumonic lobe calculated as a percentage of cardiac output during spontaneous breathing with and without pneumonia (SB, SB + PN), and duting mechanical ventilation (VENT + PN) with either CMV or HFV, Superscripts indicate statistically different group means by Kruskal-Wallis modification of ANOVA $(\mathrm{H}<0.05)$.

any experimental condition were not observed (maximum Spearman coefficient $r_{\mathrm{s}}=0.26$ ).

\section{Discussion}

This experiment compared the effects of SB, HFV, and CMV ventilation during gram negative pneumonia in sheep and demonstrated that pneumunia resulted in significant increases in $(\mathrm{A}-\mathrm{a}) \mathrm{DO}$, and $\mathrm{Qs} / \mathrm{Qt}$, as well as a significant decrease in $Q_{L L \perp \ldots}$ for time period SB. Significant differences were not observed in standard haemodynamics, (A-a)DO 2 , QsiQt and $Q_{L L L}$ when HFV was compared to CMV. Serum levels of $6-k$ eto- $\mathrm{PGF}_{1} \alpha$ were significantly elevated when HFV was compared to CMV.

The cardiopulmonary results of this experiment are consistent with previous studies. In different species with various lung injury models sustained benefit of HFV over CMV has not been demonstrated. ${ }^{1.4,17-19} \mathrm{~A}$ reduction in mean airway pressures has been observed which may result in less barotrauma. In humans, a prospective randomized trial comparing HFV to CMV in a heterogenous population of ventilated patients documented the safety and reliability of HFV but did not demonstrate any significant advantage of HFV over CMV in any regard. ${ }^{20}$

The current study is unique in that pulmonary perfusion to an isolated pneumonic segment of lung was studied in a large animal model using ventilation techniques that parallel the human situation. ${ }^{20,21}$ The experimental design provided comparisons of $Q_{L L L}$ during spontaneous breathing with and without pneumonia as well as $\mathrm{Q}_{\text {L.LL }}$ during CMV and HFV with pneumonia. Under stable conditions of gas exchange and haemodynamic parameters during pneumonia, $Q_{\text {LI... was significantly reduced }}$ when SB was compared to SB $+\mathrm{PN}$. However, no differences were recorded in the $Q_{L L L}$ after pneumonia when spontaneous breathing, CMV, and HFV were compared. Comparisons of $Q_{L L L}$ in CMV ventilated dogs with and without pneumococcal pneumonitis has been studied previously. ${ }^{7,22}$ An insignificant fall in $Q_{L L L}$ was observed $24 \mathrm{hrs}$ after pneumonitis. These reports are somewhat different from the present experiment in several areas. We did not measure $Q_{L L L}$ during either CMV or HFV without pneumonia. This would have required another ventilation period and two additional microsphere injections prior to establishment of pnetmonia. In addition, the two animal modcls differ in terms of species, the organisms causing the pneumonia, and the time frame of the experiment.

Comparisons of PBF in man and other animal models during HFV and CMV have been undertaken in lungs which were normal or involved by either lobar or diffuse injury patterns. High frequency oscillation of normal human lungs (RR $5.8-15 \mathrm{~Hz}$ ) has been shown to maintain the vertical gradient of PBF. ${ }^{5,23,24}$ Similarly, one hour after unilobar pulmonary oedema in dogs matched for alveolar pressures, no differences in PBF were observed when CMV was compared to HFV (RR $16 \mathrm{~Hz}$ ). In established diffuse lung injury induced with either oleic acid infusions, saline lavage, or meconium aspiration, there were no differences in haemodynamic vari-

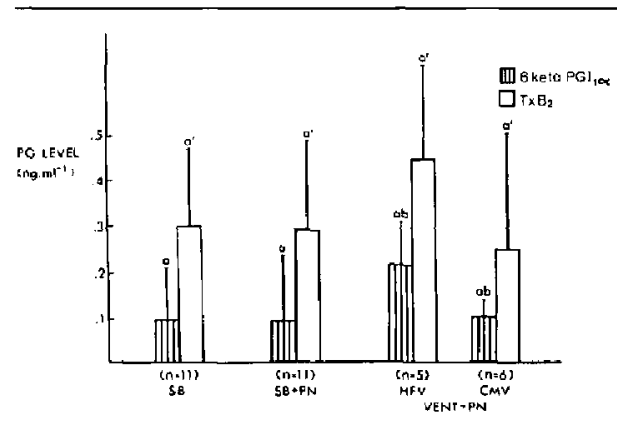

FIGURE 2 Serum levels of 6-keto-PGF $\alpha$ and $\mathrm{TxB}_{2}$ during spontaneous breathing with and without pneumonia (SB, $\mathrm{SB}+\mathrm{PN}$ ), and during mechanical ventilation (VENT + PN) with CMV and HFV. Superscripts indicate statistically different group means by KruskalWallis modification of ANOVA $(\mathrm{H}<0.05)$. 
ables including $(\mathrm{A}-\mathrm{a}) \mathrm{DO}_{2}$ and $\mathrm{Qs} / \mathrm{Qt}$ calculations during either $\mathrm{HFV}$ or $\mathrm{CMV},{ }^{17-19}$

The levels of $\mathrm{PGI}_{2}$ and $\mathrm{TXA}_{2}$ obscrved in this experiment failed to correlate with the recorded changes in $\mathrm{Q}_{\mathrm{LL}}$. A significant increase in $\mathrm{PGI}_{2}$ was observed during HFV in pneumonia. The exact significance of this finding remains unexplained. Wetzell et at. have previously shown $\mathrm{HFV}$ will significantly increase pulmonary endothelial $\mathrm{PGI}_{2}$ production in ex vivo normal sheep lungs. ${ }^{12}$ These authors attempted to explain this increase in prostacyclin production solely on the mechanical effects of rapid respiratory rates. Hypoxic pulmonary vasoconstriction is very complex metabolic event and the products of the arachadonic acid pathway synthesized by the alveolar macrophages and the pulmonary endothelium have been implicated as possible mediators of vascular and bronchial reactivity to a hypoxic stimulus. ${ }^{8}$ An inflammatory process might further complicate the normal mechanisms of compensation for ventilation/perfusion inhomogeneity. In addition, mechanical stimulation of normal lungs by increased RR and PEEP are known to alter measured serum levels of the prostaglandins $\mathrm{PGI}_{2}$ and $\mathrm{TxB}_{2} \cdot{ }^{10-12}$ Serum levels of prostaglandins and thromboxanes have been demonstrated to show marked interand intra-species variability. ${ }^{25-29}$ Evidence is accumulating which would appear to support the hypothesis that the prostaglandins and thromboxanes are important modi fiers but not the sole mediators of PBF during hypoxia. ${ }^{25-29}$ The products of the lipooxygenase segment of the arachadonic acid pathway, mamely the leukotrienes $\mathrm{LTC}_{4}$ and $\mathrm{LTD}_{4}$, appear more promising as mediators of PBF under various experimental conditions. ${ }^{29-31}$ Further work employing this model while measuring simultaneous QLLL, prostaglandin and leukotriene serum levels would be required to answer this question.

Acute unilobar gram negative pneumonia in sheep provides a clinically relevant model for the study of pneumonia in critically ill, ventilator dependent humans. In the clinical sctting of the intensive care unit, unilobar pneumonia precipitating acute respiratory failure requiring mechanical ventilation accounts for $20-40$ per cent of all admissions to medical/surgical intensive care units. ${ }^{32.33}$ As such, this experiment was designed to mimic the clinical end points of stable gas exchange and haemodynamic function during HFV or CMV. No attempt was made to equalize airway or alveolar pressures during HFV or CMV. The technical difficulty and inconsistency of such measurements would suggest these to be inappropriate end points for the purposes of our experiment. ${ }^{34}$ Because of the confounding effects of $\mathrm{PaCO}_{2}, \mathrm{PaO}_{\mathbf{2}}$ and cardiac output on gas exchange, all measurements of regional pulmonary perfusion were made during equivalent periods of gas exchange and haemodynamic function. ${ }^{6}$
The variation in the observations of $\mathrm{Q}_{\perp \mathrm{LL}}$ and the serum levels of $6-k e t o-P F_{1} \alpha$ and $T_{x B}$ were wide. This possibly reflected the fact that despite identical methodology, individual animals may have responded with differing degrees of inflammation to the gram negative bacterial challenge resulting in variations in the exact size and biochemical nature of the pneumonitis. Each animal did undergo a postmortem examination and the gruss size of the pneumonias with surrounding areas of lobar atelectasis were approximately the same. We had no definitive methodology for quantifying the pneumonia. Consequently, these minor variations may have had significant effect on the normal hypoxic vasoconstrictive response evo]ving within the LLL.

The $\mathrm{Q}_{\mathrm{LLL}}$ observed during HFV and CMV were directionally opposite. Although the differences were not statistically significant, it may reflect a differential effect on hypoxic vasoconstriction that would become more evident with a more consistent area of pneumonia and a larger study group.

The measurement of PBF using radioactive microspheres has an inherent error rate of five to ten per cent. ${ }^{35}$ This error is minimized by ensuring large numbers of injected microspheres, the air drying of all samples, a minimum number of gamma counts per sample over one minute, and ensuring satisfactory mixing of the microspheres during intravenous injection. All of these requirements were met during the current experiments and resulted in a yield of over 500 microspheres per gram of lung.

In summary, in spontaneously breathing sheep, left lower lobe pneumonitis resulted in a significant decrease in $\mathrm{Q}_{\text {LLL }}$. However, in anaesthetized sheep, there were no differences in cardiopulmonary paramcters and regional pulmonary blood flow during $\mathrm{CMV}$ as compared to HFV. HFV did result in a significant increase in serum levels of 6-keto-PGF $\alpha$ when compared to CMV only. This study demonstrates that HFV is a safe and efficient method of oxygenation and ventilation in unilobar gram negative pneumonia in sheep.

\section{Acknowledgements}

This study was supported by a grant from the Medical Research Council of Canada. The authors would like to thank M.J. Smijan for her assistance in the preparation of the manuscript.

\section{References}

I Carlon GC, Ray Jr C, Pierri MK et al. High frequency jet ventilation. Theoretical considerations and clinical observations. Chest 1982;81: 350-4. 
2 Breen $P H$, Ali J, Wood $L D H$. High frequency rentilation in lung edema: effects on gas exchange and perfusion. J Appl Physiol 1984; 56: 187-95.

3 Carlon GC, Ray Jr C, Miodownik S et al. Physiologic implications of high frequency jet ventitation techniques. Crit Care Med 1983; 11: 508-14.

4 Otro CW, Quan SF, Conahan TJ et al. Hernodynamic effects of high frequency jet ventilation. Anesth Analg 1983 ; 62: 298-304.

5 Rehder $K$, Didier EP. Gas transpert and pulmonary perfusion during high frequency ventilation in humans. J Appl Physiol 1984; 57: 1231-7.

6 Cheney FW, Colley PS. The effect of cardiac output on arterial blood oxygenation. Anesihesiology 1980; 52: 496-501.

7 Light RB, Mink SN, Wood LDH. Pathophysiology of gas exchange and pulmonary perfusion in pneumococcal lobar pneumonia in dogs. J Appl Physiol 1981; 50: 524-30.

8 Voekel NF. Mechanisms of hypoxic pulmonary vasoconstriction. Am Rev Respir Dis 1986; 133: 1186-95.

9 Said SI. Metabolic functions of the pulmonary circulation. Circ Res 1980; 50: 325-33.

10 Herbaczynska-Cedra K, Truskolanski P, Huszczul A, Dusting $G J$. Hypoventilation and elevation of end-expiratory pressure release a substance which relaxes isolated arteries and disaggregates platelets in the presence of cyclooxygenase inhibitors. Prostaglandins 1981; 21: 707-17.

II Korbut $K$, Boyd $J$, Eling $T$. Respiratory movements alter the generation of prostacyclin and thromboxane $A_{2}$ in isolated rat lungs: the influence of the arachadonic acid pathway inhibitors on the ratio between pulmonary prostacyclin and thromboxane $A_{2}$. Prostaglandins 1981; 21: 491-503.

12 Wetzell RC, Gordon JB, Gregory TJ, Gioica FR. High frequency attenuates the pulmonary vascular response to hypoxia. Abstract. Intemational symposium on High Frequency Ventilation. New York, Nov. 1983; 77-80.

13 Patterson GA, Todd TRJ. A large animal model of pseudomonas pneumonia. J Surg Res 1982; 33: 214-9.

14 Gironi MJ, Menkes E. MacDonald JWD. Hong $K$, Todd $T R J$. Effects of immunization on cardiopulmonary alterations of gram negative encotoxemia. J Appl Physiol 1984; 56: $582-89$.

15 Godfrey $K$. Comparing the means of several groups. N Engl J Med 1985; 313: 1450-6.

16 Snedecor GW. Statistical Methods. 7th Edition. Iowa State Press, lowa, USA. 192, 1980.

17 Schuster DP, Snyder JV, Klain M. Comparison of venous admixture during high frequency ventilation and conventional ventilation in oleic acid-induced pulmonary edema in dogs. Anesth Analg 1982; 61: 735-40.

18 Quan SF, Milizer HW, Calkins JW et al. Comparison of high frequency jet ventilation with conventional mechan- ical ventilation in saline-lavaged rabbits. Crit Care Med 1984; 12: 759-63

19 Mammel MC, Gordon MJ, Conneu JE, Boros SJ. Comparison of high frequency jet ventilation and conventional mechanical ventilation in a meconium aspiration model J Pediatr 1983; 103: 630-4.

20 Carlan GC, Howland WS, Ray Ir C et al. High frequency jet ventilation. A prospective randomized evaluation. Chest $1983 ; 84: 551-9$.

21 Demajo W, Redmond MD, Todd TRJ. Clinical application of HFV in the critically ill patient. R Coll Ann Phys Surg Can 1983; 16: 316.

22 Mink SN, Light RB, Cooligan T, Wood LDH. Effect of PEEP on gas exchange and pulmonary perfusion in canine lobar pneumonia. J Appl Physiol 1981; 50: 517-23.

23 Brusasco V, Knopp TJ, Schmid ER, Rehder K. Ventilationperfusion relationship during high frequency ventilation. J Appl Physial 1984; 56: 454-8.

24 Schmid ER, Knopp TJ, Rehder K. Intrapulmonary gas transport and perfusion during high frequency uscillation $J$ Appl Physiol 1981; 51: 1507-I4.

25 Gerber JG, Voekel $N$, Nies AS, McMurry IF, Reeves JT. Moderation of hypoxic vasoconstriction by infused arachadonic acid: Role of $\mathrm{PGI}_{2}$. J Appl Physiol 1980; 49: 107-12.

26 Sprague RS, Stephenson AR, Longio AJ. Prostaglandin $\mathbf{I}_{2}$ supports blood flow to hypoxic alveoli in anesthetized dogs. J Appl Physiol 1984; 56: 1254-71.

27 Voekel NF, Gerber JG, McMurtry IF, Nies AS, Reeves JT. Release of vasodilator prostaglandin $\mathrm{PGI}_{2}$, from isolated rat lung during vasoconstriction. Circ Res 1981; 48: 207-13.

28 Conzen P, Goetz A, Oetinger W, Brendel W. Hypoxic pulmonary vasoconstriction and endogenous prostaglandins and thromboxane release in anesthetized pigs. Biomed Biochem Acta 1984; 43: 5265-8.

29 Ahmed T, Oliver Jr W, Wanner A. Variability of hypoxic pulmonary vasoconstriction in sheep. Roles of prostaglandins. Am Rev Respir Dis 1983; 127: 59-62.

30 Morganroth ML. Stenmark KR, Zirrolli JA et al. Leukotriene $\mathrm{C}_{4}$ production during hypoxic pulmonary vasoconstriction in isolated rat lungs. Prostaglandins 1984; 28 : 867-75.

31 Morganroth ML, Reeves $I T$, Murphy RC, Voelkel NF Leukotriene synthesis and receptor blockers block hypoxic pulmonary vasoconstriction. J Appl Physiul 1984; 55: 1340-6.

32 Daschner F, Nadgem H, Landmack $H$ et al. Surveillance, prevention and control of hospital acquired infections. III. Nosocomial infections as a cause of death. Retrospective analysis of 1,000 autopsy reports. Infection 1978; 6: 261-9.

33 Simmons BP. Wong ES. Guidelines for the prevention of nosocomial pneumonia. In CDC: Manual of guidelines 
for the prevention and control of nosocomial infections. Springficld VA NTIS. U.S. Dept of Commerce, September 1982, 1-9.

34 Armengo! J, Jones RL, King $G$. Alveolar pressures and lung volumes during high frequency oscillatory ventilation. Crit Care Med 1985; 13: 632-6.

35 Buckberg GD. Luck JC. Payne B et al. Some sources of error in measuring regional blood flow with radioactive microspheres. J Appl Physiol 1971; 31: 598-604.
Résumé

On a comparé les effets de la ventilation a haute fríquence en jet ( $H F \mathrm{~V}$ ), la ventilation conventionnelle (CMV), et la respira. tion spontanée $(S B)$ sur les flots régionaux pulmonaires $\left(Q_{L L L}\right)$. les paramètres hémodynamiques standards et le niveau sérique des métabolites de première génération de la prostacycline $\left(6-k e t o-P G F_{1} \alpha\right)$ et le thromboxane $A_{2}\left(T x B_{2}\right)$ chez 11 moutons atteints d'une pneumonie lobaire inférieure gauche à pseudomonas aéroginose. La pretumonie à gramme négatif a amené l'augmentation significative des gradients alvélo-artériels de l'axygène [( $\left.\mathrm{A}-\mathrm{a}) \mathrm{DO}_{2}\right]$ et des fractions de shunt pulmonaire (Qs/Qt), ainsi qu'une diminution signifucative du $Q_{u L}$ durani la respiration spontanée. Des différences significatives dans des paramètres hémodynamiques, $(A-a) D O_{2}, Q s / Q t$, et $Q_{W L}$ n'étaient pas observées quand le HFV était comparé au CMV. Cependant, le niveau sérique du 6-keto-PGF, $\alpha$ étail élevé quand les animatx étaiemt sous $H F V$. On conclue que le $H F V$ est securitaire et efficace pour l'ongériation et la ventilation lors d'une pneumonie unilobaire d̀ gramme négarif et qu'elle amène une augmentation significative des niveanx sériques du 6-keto-PGF $\alpha$ comparativement à la CMV chez les moutons. La significarivité exacte de cette dernière trouvaille est encore sujatte d̀ l'investigation. 